UDC 621.89.012.7

O. V. Blinov ${ }^{1}$, V. A. Godlevskiy ${ }^{2}$, Yu. N. Moiseev ${ }^{3}$, A. S. Parfenov ${ }^{4}$

\title{
CORRELATION BETWEEN STRUCTURAL AND TRIBOLOGICAL CHARACTERISTICS OF SOME MESOMORPHIC BOUNDARY LUBRICATION LAYERS
}

\author{
${ }^{1}$ Ivanovo State Polytechnical University, \\ 21 Sheremetevsky Ave., Ivanovo, 153000, Russia. \\ ${ }^{2}$ Ivanovo State University, \\ 39 Ermak St., Ivanovo, 153025, Russia. E-mail: god1@yandex.ru \\ ${ }^{3}$ Ivanovo Rescue and Fire Fighting Academy of the State Fire Service, \\ 33 Stroiteley Ave., Ivanovo, 153040, Russia \\ ${ }^{4}$ Ivanovo State Medical Academy, \\ 8 Sheremetevsky Ave., Ivanovo, 153012, Russia
}

The article is devoted to the epitropic orderliness of mesogenic lubrication material in boundary layer. The modelling of tribo-system with boundary lubrication layer by means of management of the software realizing methods of the molecular mechanics, quantum chemistry and molecular dynamics has been carried out. During modelling the virtual lubrication layer of the designated thickness with randomized initial molecules arrangement was built. Further procedure included the minimization of molecular system energy by corresponding optimization of molecules orientation in the lubrication layer. Modelling solid surfaces of friction took place at a certain distance in parallel to each other. The lubricant was placed between these surfaces. The value of lubricant's molecular cluster orientation factor was counted in the process of iteration of periodic virtual shear of the top surface relative to bottom and consequent optimization process taking into account an arrangement of molecules concerning surfaces.

Tests of some lubrication substances which molecules possessed anisometric form and, hence, propensity to supramolecular self-organizing in the lubricant layer have been conducted. For comparison of experimental results, the correlation dependence between modeling and experiment was built. It confirms the reliability of molecular modeling data for prediction of antifrictional properties of mesogenic lubricating materials.

Key words: boundary lubrication layer, epitropic phase, mesogen, molecular modeling, molecular dynamics, lubricant, friction coefficient, correlation.

DOI: $10.18083 /$ LCAppl.2019.2.76

(C) Blinov O. V., Godlevskiy V. A., Moiseev Yu. N., Parfenov A. S., 2019 


\title{
О. В. Блинов ${ }^{1}$ В. А. Годлевский느, Ю. Н. Моисеев ${ }^{3}$, А. С. Парфенов ${ }^{4}$
}

\section{КОРРЕЛЯЦИЯ МЕЖДУ СТРУКТУРНЫМИ И ТРИБОЛОГИЧЕСКИМИ ХАРАКТЕРИСТИКАМИ МЕЗОМОРФНЫХ ГРАНИЧНЫХ СМАЗОЧНЫХ СЛОЕВ}

\author{
${ }^{1}$ Ивановский государственный политехнический университет, \\ Шереметевский пр., д. 21, 153000 Иваново, Россия. \\ ${ }^{2}$ Ивановский государственный университет, \\ ул. Ермака, д. 39, 153025 Иваново, Россия. E-mail: godl@yandex.ru \\ ${ }^{3}$ Ивановская пожарно-спасательная академия Государственной противопожарной \\ службы МЧС России, пр. Строителей, д. 33, 153040 Иваново, Россия \\ ${ }^{4}$ Ивановская государственная медицинская академия, \\ Шереметевский пр., д. 8, 153012 Иваново, Россия
}

Статья посвящена эпитропной упорядоченности мезогенного смазочного материала в граничном слое. С помощью методов, основанных на молекулярной механике, квантовой химии и молекулярной динамике было выполнено моделирование трибосистемы с граничным смазочным слоем. В прочессе моделирования был построен виртуальный смазочный слой заданной толщины с рандомизированным позиционированием составляющих его молекул. Дальнейшая процедура включала в себя минимизаџию энергии молекулярной системы и соответствуюшую ей оптимизацию молекулярной ориентации частии в смазочном слое. Моделирование твердых поверхностей трения происходило путем построения двух параллельных виртуальных плоскостей. Смазочный материал помещался этими двумя поверхностями. В процессе пошагового виртуального сдвига верхней поверхности относительно нижней производили оптимизацию взаиморасположения молекул и рассчитывали ориентачионный коэффициент молекулярного кластера относительно поверхностей.

Были проведены опыты с использованием смазочных материалов, имеющих анизометрию формы молекулы и, таким образом, способных к надмолекулярной самоорганизации в смазочном слое. Для сравнения результатов эксперимента была определена корреляционная зависимость между экспериментальными и расчетными данными. Это подтвердило пригодность молекулярного моделирования для предсказания антифрикиионных свойств мезогенных смазочных материалов.

Ключевые слова: граничный смазочный слой, эпитропная фаза, мезоген, молекулярное моделирование, молекулярная динамика, смазочный материал, коэффициент трения, корреляиия.

\section{Introduction}

At present use of methods of molecular modelling in theoretical tribology starts to extend quickly [1]. These calculations help to estimate the effects arising directly at a friction of metal and/or nonmetallic surfaces in vacuum, in the presence of liquid lubricant or nanoparticles. In this connection researches on presence or absence of «third body» in a contact zone can be classified as 1) at a solid friction with lack of any environment $[2,3,4] ; 2)$ in gas environment or in the presence of air; 3 ) in the presence of thin dividing films in condensed condition; 4) in the presence of lubrication films [1, 6], including ionic liquids [7].

The majority of works on friction research at atomic level is investigated by friction surfaces with well ordered structure. In particular, they analyze atomi- cally smooth surfaces of graphite, silicon, glass, tungsten, diamond and other materials. Researches can differ also by form of potentials considered in model: these are fields created by solid walls and also lubricant particles. Calculation of potentials demands significant computing resources and depends on the nature of bounds in participating in friction materials [8].

According to the research data received in this area all investigation can be distinguished by: 1) changes of structure of solid surfaces; 2) wear; 3) micro-rheology of lubrication layers; 4) orientational processes in lubricant (supramolecular self-organising) [9]; 5) antifrictional effects.

Of the above tasks, we are most attracted to the process of formation in the lubrication layer of epitropic mesophase under influence of shear process [10]. The practical perspective of this phenomenon was first 
assessed by Dr. Sc. I.G. Chistyakov who suggested using mesogenic substances as lubricants [11].

In the present work we have paid special attention to construction of model of complicated tribosystems with two solid surfaces and the lubrication layer consisting of mesogene molecules. It would be interesting to establish interrelation between order degree of mesomorphic layer and antifrictional effect of molecular-ordered layer.

\section{The principle of computer molecular model construction for tribosystem with lubrication layer}

Tribosystem with lubrication component in the most general, simplified modelling representation shows the structure including, at least, five separate layers: two solid surfaces, two «degenerate» superficial adsorption layer and a «volume» layer of lubrication material (LM). In the course of friction LM is exposed to shear that involves continuous evolution, self-organizing of molecules in lubrication layer. Taking into account this obstacle it is possible to imagine, in what sequence (by a principle «from simple to complex») it is necessary to develop models of tribosystem to come nearer to understanding of structure and functioning characteristics of all its elements.

To come to consideration of specific friction process in its dynamic development it is necessary to first divide the tribosystem into elements of molecular scale and to build the «static» model. In the process of complication, it is possible to construct the following hierarchy of elements of such «static» tribosystem.

1) Model of an individual molecule of LM.

2) Model of structurally organized «clusters» of two solid friction surfaces.

3) Model of singular adsorption complex (the LM molecule + small area of solid surface).

4) Model of non-adsorbed cluster of LM homotypic molecules, considering interaction of particles among themselves inside this cluster.

5) Model of adsorbed monolayer of LM molecules on solid surface.

6) Model of adsorbed «multilayer» extended to extra limits of adsorption volume (boundary layer) in the area of hydrodynamic part of lubricating film.

7) Model of integral tribosystem taking into account internal interaction between its elements.

Certainly, at the initial stages of modelling it is necessary to resort to strong restrictions and assumptions: 1) to consider the lubricant layer consisting of molecules only of one type; 2) to neglect chemisorption; 3 ) to assume the constancy of temperature and not to consider the temperature gradients; 4) to be limited rather to small number of adsorbate molecules.

The given modelling objects initially should be under construction «in statics», and only at the following stage these virtual systems can be «actuated»: to enter fields of speeds, normal and shear stresses et cetera. Only at this stage the reception of substantial tribological information - for example, a settlement estimation of friction factor - will be possible.

The important role at modelling of such complex system is played by the type of optimization procedure to be applied. These procedures strongly differ in nomenclature of considered interactions, accuracy and calculations productivity. Some useful recommendations in this respect are given in work [12]. At ours modelling we used the «semi-empirical» method of $\mathrm{MM} 2+$.

A good deal of software is offered in the market intended for modelling of molecular systems with use of methods of molecular dynamics. However, there is no program serving to estimating the efficiency of lubrication properties of investigated materials and not requiring additional extensive knowledge in program guidance and theoretical base that makes useless application of such packages as a tool base of the engineer engaged in research and development of LM. At the same time studying of properties of components of antifrictional substances at molecular level allows to expand a range of estimated properties of lubricants and, hence to raise quality and completeness of their estimation, that, in turn, allows to develop new efficient LM.

Our purpose was to create the technique and software for computer molecular modelling of tribosystems with taking into account the role of each component of lubrication layer. It would allow to replace the natural physical experiment with the virtual one with automatic fulfillment of experiments with each component of a lubricant layer. Virtual experiment was spent by means of the software management, realizing methods of molecular mechanics, quantum chemistry and molecular dynamics. Thus, the program complex consisting of the base optimizing block and additional program modules developed by us was used. The system made of these elements, worked as whole at the expense of interprogram communication protocols and the internal programming language. The basic structure of the program complex created by us has been described in work [13]. 


\section{Assumptions and restrictions on construction and work of the program complex}

By far not every system can be analyzed by the method described above. We consider useful to list those difficulties of restriction and assumption which accompany the application of molecular dynamics methods for the description of processes within interphase borders in the conditions of shear deformation at friction.

\section{A. Modelling of solid friction surfaces}

1. It is difficult to introduce into the model the degree of perfection of crystal lattice (modelling of defects of structure of surfaces), "depth" (quantity of layers) in models of solid surface.

2. In comparison with metals the modelling of the nonmetallic surfaces consisting of large complex molecules (polymer, elastomer, textile fiber, composite etc.) is uneasy.

3. It is not clear how to carry out modelling of surfaces roughness as the characteristic size of these roughness obviously significantly exceeds the size of a modelled zone of contact.

\section{B. Modelling of liquid dividing layer of LM}

1. The big sizes of lubricant molecule limit the possibilities of optimization.

2. The quantity of particles in modelled adsorbate cluster (volume of working space in which shear process is investigated) is limited. The statistics for calculation of molecular orderliness can be insufficient when dealing with small number of particles.

3. It is very difficult to track molecular conformations common for complex molecules.

4. The presence of solvent in LM will cause additional difficulties and also in this regard the tracking of tribo-active component concentration.

\section{The software type, settlement algorithms}

1. The choice of optimization method and its program realization, presence of optimizing block and the necessary additional program blocks developed specially for the description of tribo-systems is important. It is useful to search for the possibilities for «parallel computing» and calculation of tribo-system with many particles on multiprocessing computer systems.

2. For restriction of calculations amount the introduction of limited «effective interaction radiuses» between LM cluster particles is necessary.
3. The size of digitization step of shear process is important.

4. Search of possibilities of process temperature account is required at modelling since the temperature account is practically impossible currently.

5. The recording of computing speed presents a problem since the calculation in real time is impossible.

6. The proved choice of effective counted parameter is necessary for quantitative estimation of orderliness of tribosystem.

\section{Characteristics of applied computer technics}

1. Increasing of computer CPU speed is desirable.

2. The increase in number of particles (atoms and molecules) in investigated tribosystem would lead to increase of accuracy and reliability of counted estimations. The transition to calculations on multiprocessing computer systems would be useful for it.

As quantitative estimation of supramolecular orderliness of LM molecular cluster the so-called orientation factor (order parameter), introduced by V.N. Tsvetkov [14], has been used which helps to estimate the degree of molecular system's supramolecular orderliness, in this case - lubrication layer. Values of this factor with perfect uniaxial orientation is accepted as one whereas full disordering assigns it a zero value [15]. In our software the calculation procedure for finding the orientation factor can be divided into 3 steps:

1. Calculation of «director-vector» (molecular axis) coordinates of an individual LM molecule.

2. Calculation of preferential direction of molecular orientation in all cluster.

3. Calculation of orientation factor on the basis of calculated corners between the shear direction and axis of each molecule.

In the software developed by us, the vector of molecular axis can be calculated by two methods - a least-squares method (LSM) and more simple empirical method. Three-dimensional LSM is the most accurate method which can be applied to any molecules, however, it demands the big computing resource, and when working with a big number of cluster particles significantly slows down calculations speed.

The simplified method of molecular axis position finding consists of calculating extreme two atoms on the one end of the molecule and one more atom as far as possible from the first two. The given simplification starts with the assumption, that molecules, which oriental 
factor is calculated, are not deformed in the course of calculation of molecular dynamics, or deformation of these molecules can be neglected. This second method is more convenient for calculations because of its speed.

Thus, having found one of the described above ways the three-dimensional equation of straight line, we can find a prevailing direction along which the greatest quantity of molecules is located, and we choose it for the main average direction. Corners of an inclination of the direction to co-ordinate axes are used for calculation the orientation factor in cluster of LM.

The example of tribosystem virtual model construction has been executed. As modelling LM was accepted glycerine since it is a material which molecule possesses a symmetry axis. Rather small size of glycerine molecule has allowed to create the cluster of 400 molecules. $\alpha$-iron lattice has been chosen as a material of solid surface.

For simplification of the system the surface model has been accepted as strictly fixed (internuclear distances are strictly set according to the parameters of crystal lattice of the given material). I.e. optimization of the particles mass was not fulfilled, and it has led to saving of computing resource.

Further, we modelled the LM cluster, for subsequent drawing together of surfaces under action of in termolecular forces. Drawing together was modelled by the inclusion of optimizing procedure before achieving the condition of adsorption balance (a minimum of energy of interaction of the particles entering into system). The surface area cluster and adsorbing substance were combined, their optimization was carried out, full energy of system, energy of adsorption to the surface and orientation factor were calculated.

\section{The software for computed estimation of supramolecular orderliness degree in boundary lubrication layer}

We had developed the software intended for computing estimation of LM efficiency by means of replacing the physical experiment to virtual using software realizing methods of molecular mechanics. The algorithm of comparative research of lubricants consists of the following steps:

1. One molecule of LM was modelled with the help of molecular modelling software realizing methods of the molecular mechanics, molecular dynamics and quantum chemistry (see for example, Fig. 1 where the glycerine molecule is presented).

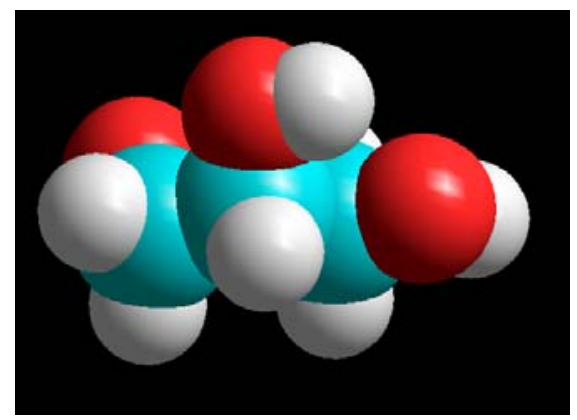

Fig. 1. Model of glycerine molecule $\mathrm{C}_{3} \mathrm{H}_{5}(\mathrm{OH})_{3}$

2. By means of the protocols of interprogram communication built into our software for managing the optimizing block the model of LM layer of the set sizes with randomized arrangement of molecules was created. The procedure of tribo-system energy minimization and optimization of molecules positions in the lubrication layer (the example of generated molecular cluster is shown on Fig. 2) has been executed.

3. In the following step by means of our software the friction surfaces of defined size have been con- structed and placed parallel to each other on the set distance corresponding to the thickness of the lubrication layer. The lubrication layer was placed between the solid surfaces.

4. After that the interphase superficial energy was calculated by defining the difference of system energies before the interaction of the lubrication layer with surfaces and after it. The example of the program window and calculation results are shown on Fig. 3. 


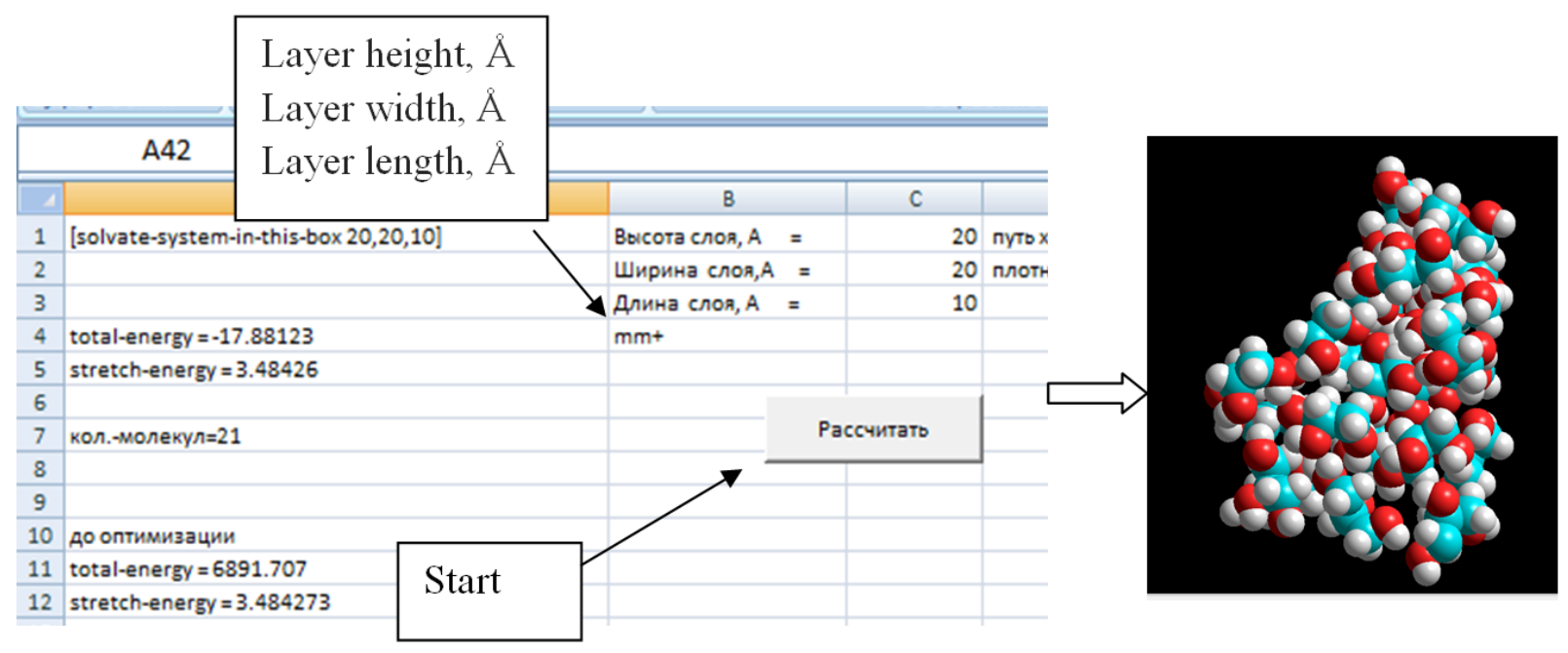

Fig. 2. Program block for LM cluster optimizing

5. A number of virtual cyclic shifts of the top friction surface relative to the bottom one was made while conserving the parallel position of the surface. The optimization process of molecules positions based on minimum energy of intermolecular interaction was repeated after each elementary shift (Fig. 3).

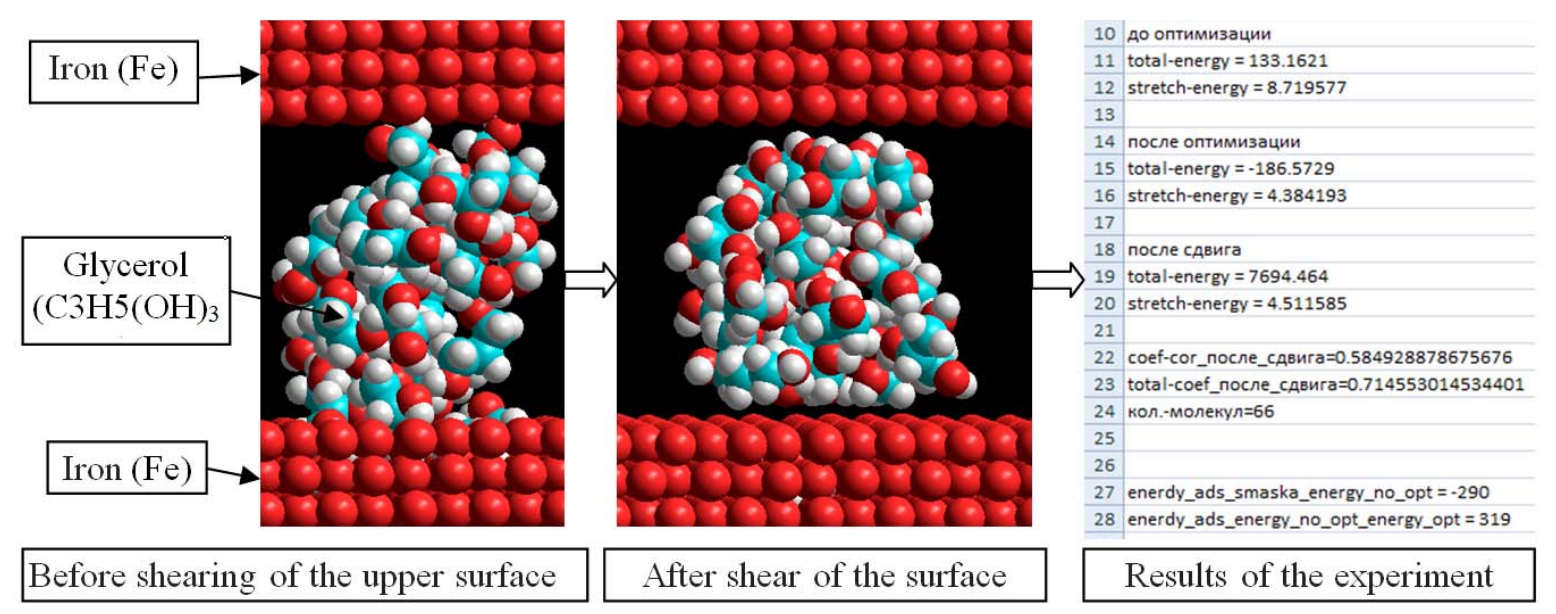

Fig. 3. Scheme of shear process in virtual tribo-system

6. The order parameters for the cluster are calculated: oriental factor (absolute parameter of order), and also factor of orderliness of molecules in the lubrication layer $S$ estimating orientation of cluster molecules relative to the vector of sliding direction:

$$
S=\frac{\delta(\cos \alpha)+\delta(\cos \beta)+\delta(\cos z)}{3}
$$

where $\delta(\cos \alpha), \delta(\cos \beta), \delta(\cos z)$ - standard deviations of all molecules axes directing cosines relative to coordinate axes.
For separate estimation of the order parameter by coordinates the parameter $S$ is calculated relative to three axes by the formulas:

$$
\begin{aligned}
& S_{x}=\frac{1}{2}\left\langle 3 \cos ^{2} \theta_{x}-1\right\rangle, \\
& S_{y}=\frac{1}{2}\left\langle 3 \cos ^{2} \theta_{y}-1\right\rangle, \\
& S_{z}=\frac{1}{2}\left\langle 3 \cos ^{2} \theta_{z}-1\right\rangle .
\end{aligned}
$$

where $\theta$ - the corner between an axis of individual molecule and the given axis (angular brackets mean averaging on all the orientations of molecules). 
7. By means of molecular modelling program the potential energy of system is automatically computed.

\section{Experimental estimation of molecular dynamics parameters calculation results}

To establish the correlations between calculated and experimental parameters of tribosystem, the cycle of tribosystem molecular modelling with various lubricants and the corresponding tribotechnical experiment was executed. The virtual tribosystems were constructed in which iron was a material of solid surfaces. Mesogenic chemicals of the different nature: 1) decanol, 2) glycerin, 3) oleic acid, 4) disodium salt of sulphonic siccine acid (DNSA) - nonionic surfactant, 5) neonol 9-12 - nonionic surfactant were used as model LMs.

Calculations of molecular dynamics were carried out in the sequence described above. We have created the virtual tribosystem with a number of LM molecules
300-800 and carried out on it the procedure of microshear of the top surface on the distance comparable with the length of the molecule. After each step the system was optimized based on minimum of energy and the order parameters were calculated: orientation factor $S$ (degree of orientation without allocated directions) and orderliness factor $S_{\mathrm{x}}$ (orientation evaluation relative to the vector of sliding direction).

The natural tribotechnical experiments on measurement of friction factor with all LM have been made. The small-sized tribometer TAY-1 was applied. The friction couple was executed under the scheme «pinplane» at back and forth motion of flat surface relative to indenter. The material of both friction surfaces used was carbon steel 45. Average sliding speed was $2,5 \mathrm{~cm} / \mathrm{s}$, normal loading $-0,1 \mathrm{~N}$ was put on a sliding plane. Temperature $-22{ }^{\circ} \mathrm{C}$. The lubricant was once brought onto the sliding plane before each test. The results of molecular modelling and tribotechnical tests are presented in Table 1.

Table 1. Results of tribosystem research with various mesogenic LM

\begin{tabular}{|c|c|c|c|c|c|}
\hline $\begin{array}{l}\text { Lubrication } \\
\text { material }\end{array}$ & 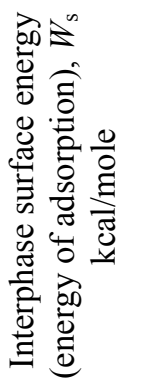 & 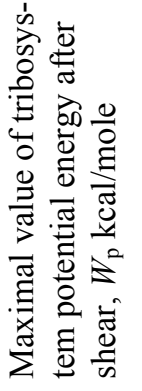 & 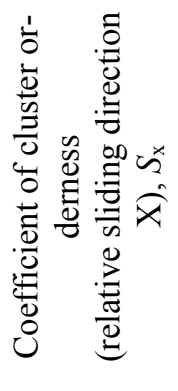 & 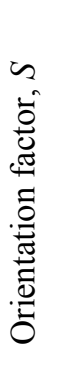 & 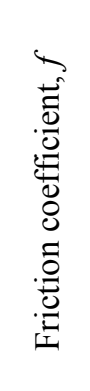 \\
\hline DNSA & 1733 & 6357 & 0.48 & 0.68 & 0.046 \\
\hline Neonol 9-12 & 1408 & 6220 & 0.45 & 0.58 & 0.043 \\
\hline Oleic acid & 8,75 & 6167 & 0.41 & 0.63 & 0.042 \\
\hline Decanol & 1135 & 6149 & 0.61 & 0.71 & 0.040 \\
\hline Glycerin & 90 & 5700 & 0.63 & 0.74 & 0.035 \\
\hline
\end{tabular}

The calculation showed that glycerine has the smallest values of potential energy of system at shift of the top surface of friction (which correlates with the shift pressure), thus the same substance possesses the biggest factor of orderliness of molecules. DNSA has the biggest value of adsorption energy and the biggest value of shift pressure. Based on the results of the experiment, glycerine provides the smallest pressure of shift and also possesses the smaller factor of friction.

To show the stochastic correlation between the calculated parameters of molecular cluster and friction factor, the multiple correlation between four computed parameters and friction factor was calculated. The results are presented in the form of matrix of multiple correlation where force of correlation bound is presented by Pearson's factor. 
Table 2. The matrix of multiple correlation between friction factor and computed parameters of molecular modelling

\begin{tabular}{|c|c|c|c|c|c|}
\hline & $W_{s}$ & $W_{\mathrm{p}}$ & $S_{\mathrm{x}}$ & $S$ & $f$ \\
\hline$W_{\mathrm{s}}$ & 1 & & & & \\
\hline$W_{\mathrm{p}}$ & 0,712 & 1 & & & \\
\hline$S_{\mathrm{x}}$ & $-0,127$ & $-0,669$ & 1 & & \\
\hline$S$ & $-0,246$ & $-0,581$ & 0,859 & 1 & \\
\hline$f$ & 0,698 & 0,969 & $-0,744$ & $-0,602$ & 1 \\
\hline
\end{tabular}

Based on Table 2 it is evident that the greatest value of Pearson's factor corresponds to function $f\left(W_{\mathrm{p}}\right)$. This dependence is presented on Fig. 4. The diagram shows that the factor of linear correlation between the counted estimation of shear resistance of lubricant by molecular modelling and experimentally measured friction factor gives $R=0,969$.

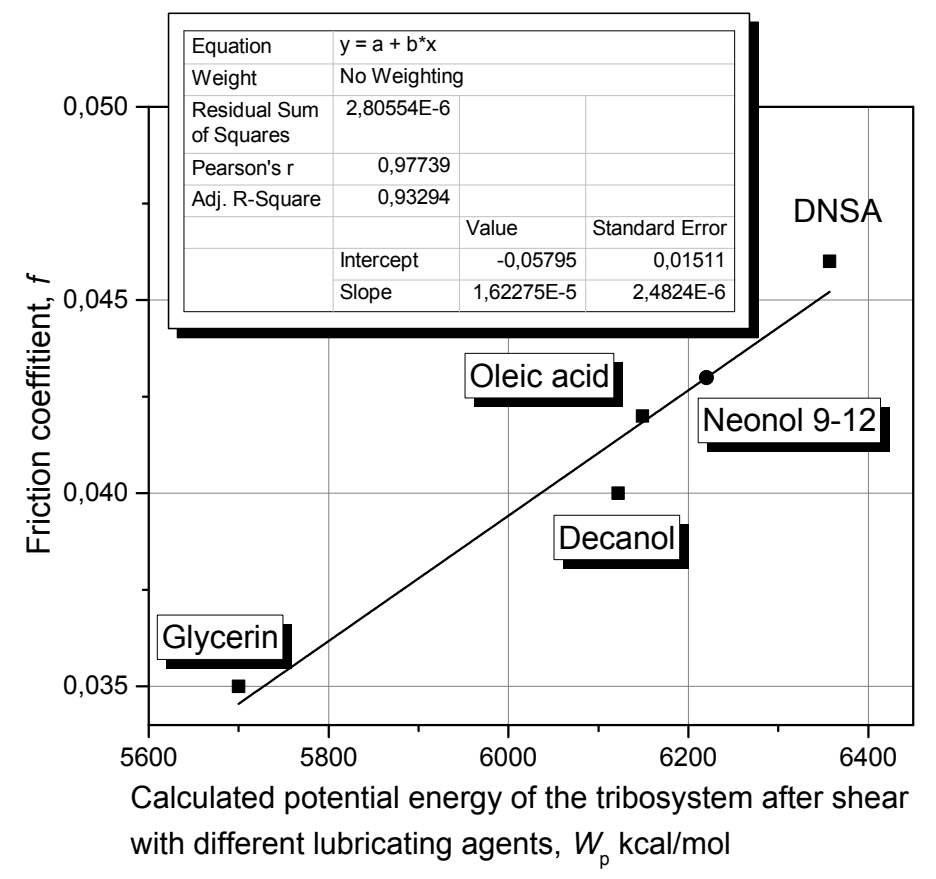

Fig. 4. The correlation dependence between friction factor and counted parameter $W_{\mathrm{p}}$

\section{Conclusion}

Thus, in the present work the examples of molecular dynamics methods application for the description of processes on border of firm and liquid phases in a friction zone have been shown. Methods of calculation of molecular parameters of the lubricant layer formed by mesogene molecules capable to show the orientational effects have been offered. These parameters described the lubrication layer energy in static condition and at virtual shear.
Besides, we have counted the molecular order parameters in lubricant layer which at molecular level is oriented during shear. Experiments on measurement of friction factor in different mesogene environments have shown that shear resistance has significant correlation with computed parameters of molecular modelling. It means that calculations of molecular dynamics allow to predict the tribological properties of «structurally-active» lubricants and, hence, to help with creation of new lubrication compositions. 


\section{References}

1. Godet M. Modeling of friction and wear phenomena. Proceedings of the Workshop on the Use of Surface Deformation Models to Predict Tribology Behavior. New York, Columbia University, December 17-19, 1986, 12-36.

2. Ewen J.P., Gattinoni C., Thakkar F.M., Morgan N., Spikes H.A., Dini D. Nonequilibrium Molecular Dynamics Investigation of the Reduction in Friction and Wear by Carbon Nanoparticles Between Iron Surfaces. Tribol. Lett., 2016, 63 (3), 38.

DOI: $10.1007 / \mathrm{s} 11249-016-0722-7$.

3. Li Y., Wang S., Wang Q. A molecular dynamics simulation study on enhancement of mechanical and tribological properties of polymer composites by introduction of graphene. Carbon, 2017, 111, 538-545.

4. Brostow W., Simões R. Tribological and mechanical behavior of metals and polymers simulated by molecular dynamics. Journal of Materials Education, 2005, 27 (1-2), 19-28.

5. Zheng X. Molecular dynamics simulation of boundary lubricated contacts. A dissertation submitted for the award of the degree of $P h D$. University of Wollongong School of Mechanical, Materials and Mechatronics Engineering, 2014, 218 p.

6. Ewen J. Non-equilibrium molecular dynamics simulations of organic friction modifiers. Works of STLE Annual Meeting. Imperial College London, 19th May 2016.

7. Carper W.R., Wahlbeck P.G., Nooruddin N.S. SemiEmpirical Molecular Modeling of Ionic Liquid Tribology: Ionic Liquid-Aluminum Oxide Surface Interactions. Tribol Lett., 2011, 43, 163-168.

DOI: $10.1007 / \mathrm{s} 11249-011-9795-5$.
8. Dong Y., Li Q., Martini A. Molecular dynamics simulation of atomic friction: A review and guide. Journal of Vacuum Science \& Technology. A, 2013, 31, 030801. DOI: $10.1116 / 1.4794357$.

9. Cheng-Da Wu, Jen-Fin Lin, Te-Hua Fang. Molecular dynamic simulation and characterization of self-assembled monolayer under sliding friction. Computational Materials Science, 2007, 39, 808-816.

10. Godlevskiy V.A., Usol'tseva N.V. The surface phenomena and mesomorphism. Ivanovo, Ivanovo State University, 2010, 186 p. (in Russ.).

11. Patent of USSR, № 601304. Cutting fluid for metal treatment / V.N. Latyshev, V.B. Karabanov, V.M. Chaykovskiy, I.G. Chistjakov; priority from 27. 04.78.

12. HyperChem ${ }^{\circledR}$. Computational Chemistry: Part 1. Practical Guide / Part 2. Theory and Methods. Hypercube inc., 2002, 373 p.

13. Kuznetsov S.A., Godlevskiy V.A., Berezina E.V., Bogomolov M.V. A Software Complex for Molecular Simulation of Boundary Lubrication Layers. Journal of Friction and Wear, 2012, 33 (1), 5-10.

DOI: $10.3103 / \mathrm{S} 1068366612010084$.

14. Pikin S.A., Blinov L.M. Liquid crystals. Moscow : Nauka, 1982, 280 p. (in Russ.).

15. Godlevskiy V.A., Blinov O.V. Computing of the Molecular Orientation State of the Lubrication Layer. Procedia Engineering, 2016, 150, 584-589.

DOI: 10.1016/j.proeng.2016.07.046. 